\title{
Contribution of different body segments in Sit and Reach Test
}

\author{
Contribuição dos Diferentes Seguimentos Corporais no Teste de Sentar e \\ Alcançar
}

Andrea Perin ${ }^{1}$, Leandra Ulbricht ${ }^{1}$, Eduardo Borba Neves ${ }^{1 *}$

ARTIGO ORIGINAL | ORIGINAL ARTICLE

\begin{abstract}
This research aims to determine the contributions of the hip joint, lumbar and thoracic spine in the execution of Sit and Reach (SR) in young Brazilians. Subjects were 195 boys from 18 to 19 years. Sit and Reach was evaluated with angular kinematic analysis through of Photogrammetry to identify the contribution of body segments in trunk flexion. A protocol was developed for evaluating reference angles that were transformed into percentage contribution of the segments. Based on the results, it was possible to create a table of classification of angles and percentages, which allowed the identification of compensation movement. It was possible to conclude that the contributions of the thoracic spine, lumbar spine and hip in performing the SR are $46.01 \pm 7.32 \%, 12.68 \pm 5.12 \%$ and $41.31 \pm 7.19 \%$ respectively. It is recommended that evaluations of flexion of the hip joint, thoracic and lumbar spine are performed separately by photogrammetry.
\end{abstract}

Keywords: Hip joint; spine; range of motion; photogrammetry

RESUMO

Esta pesquisa objetiva determinar a contribuição da articulação do quadril, da coluna lombar e torácica na execução do Teste de Sentar e Alcançar (TSA) em jovens brasileiros. A amostra foi composta por 195 rapazes de 18 a 19 anos. Para identificar a contribuição dos segmentos corporais no movimento de flexão do tronco, realizou-se juntamente com o TSA uma análise cinemática angular por meio de Fotogrametria. Para tanto, desenvolveu-se um protocolo de avaliação de ângulos de referência que foram transformados em percentuais de contribuição dos segmentos. Com base nos resultados, foi possível criar uma tabela de classificação dos ângulos e percentuais, que permitiu identificar compensações no movimento. Pôde-se concluir que as contribuições médias da coluna torácica, da

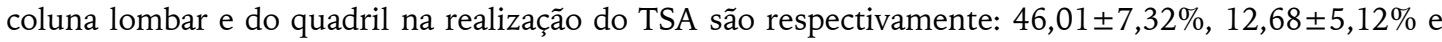
$41,31 \pm 7,19 \%$. Recomenda-se que a avaliação da flexão da coluna torácica, da coluna lombar e do quadril seja realizada separadamente, por fotogrametria.

Palavras-chaves: Articulação do quadril; coluna vertebral; amplitude articular; fotogrametria

Manuscript received October $17^{\text {th }}, 2014$; Accepted May 26 ${ }^{\text {th }}, 2015$

${ }^{1}$ Graduate Program in Biomedical Engineering, Federal Technologic University of Paraná - UTFPR, Curitiba, Brazil

* Corresponding author: Sete de Setembro Ave 3165, 80230-901, Curitiba, PR, Brazil E-mail: borbaneves@hotmail.com 


\section{INTRODUCTION}

The ageing process alters body composition, including increases in adiposity and decreases in muscle mass (MM) (Baumgartner, 2000; Baumgartner, Waters, Gallagher, Morley, \& Garry, 1999; Doherty, 2003; Forbes \& Reina, 1970; Lang et al., 2010). Reduction in MM due to ageing is one of the most important factors, since it directly impacts the functionality of elderly (Baumgartner et al., 1998; Janssen, 2006), by reducing muscular strength and power (Deschenes, 2004), this condition is commonly called sarcopenia. The more pronounced changes occur in women, especially after menopause and constitute a major public health problem (Janssen, Heymsfield, \& Ross, 2002).

The hip flexion and extension movement of the knee results in the trunk flexion and, consequently, the stretching of the hamstring muscles, which are characterized as biarticular muscles, with different features, which provides a higher concentration of fast twitch muscle fibers. As a result, these attributes imposes a condition of tendency to muscle shortening (Alter, 1991; Ayala \& Sainz, 2011; Davis, Ashby, Mccale, Mcquain, \& Wine, 2005).

This shortening is listed as a factor that contributes to the appearance of diseases and pain syndromes such as muscle strain, low back pain, patellofemoral joint dysfunction, pubic pain, postural deviations, patellar tendinitis, a reduction in physical performance, gait limitations and risk of falling in adults (Ayala \& Sainz, 2011; Baltaci, Un, Tunay, Besler, \& Gerçeker, 2003; Cailliet, 1988; Castro-Piñero Et Al., 2009; Jones, Rikli, Max, \& Noffal, 1998; Kawano Et Al., 2010; Lemmink, Kemper, Greef, Rispens, \& Stevens, 2003; Patterson, Wiksten, Ray, Flanders, \& Sanphy, 1996).

According to López-Miñarro et al (2007), the Sit and Reach Test (SR) is the most common test to assess hamstring flexibility. Although widely used, many studies have questioned its use (Ayala \& Sainz, 2011; Cardoso, Azevedo, Cassano, Kawano, \& Âmbar, 2007;
Cornbleet \& Woolsey, 1996; Hoeger, Hopkins, Button, \& Palmer, 1990; López-Miñarro, Andújar, \& R., 2009; Perin, Ulbricht, Ricieri, \& Neves, 2012), because they believe that some factors can contribute to change the result, for example, the difference in length between the proportion of upper and lower limbs, the flexibility of the spine and scapular abduction. Thus, these factors have motivated the creation of several modified versions of SR.

However, some studies have observed that SR and its modified versions showed similar validity for assessing hamstring, but no relation to the evaluation of lumbar flexibility, thus indicating that the tests are similar and have only some methodological variations (Baltaci Et Al., 2003; Chung \& Yuen, 1999; Danny, Chu, Luk, \& Hong, 1998; Jackson \& Baker, 1986; Liemohn, Sharpe, \& Wasserman, 1994; Miyazaki, Murata, Horie, \& Suzuki, 2010).

According to Kendall et al. (1965), the postures adopted by the thoracic and lumbar spine are not distinguished in the SR score, but their behavior is extremely decisive to establish the real condition of elasticity of the hamstrings or flexibility of the hip or spine joints. Perin et al.(2013), using the technique of photogrammetry, have proposed a new test in order to develop a test to evaluate the mobility of body segments participants. It has allowed to observe the contribution of the spine and joint hip in motion through kinematic analysis,. However, classification parameters are necessary to identify the optimal use of the motion segments and compensation mechanisms that can be generated by the lack of flexibility.

Therefore, the aim of this study is to determine the contribution of the hip joint, lumbar and thoracic spine in the execution of SR in young Brazilians. The identification of the normal limits for young adults can serve as reference for other age groups, since the peak values of physical valences are generally achieved in this age group. 


\section{METHOD}

\section{Participants}

The subjects that volunteered to participate in the study were 195 young males between 18 and 19 years old, with Body Mass Index (BMI) below $30 \mathrm{~kg} / \mathrm{m}^{2}$. The average body weight was $69.10 \pm 10.21 \mathrm{~kg}$ and average height was $1.76 \pm 0.07 \mathrm{~m}$, resulting in a BMI of $22.20 \pm 2.76 \mathrm{~kg} / \mathrm{m}^{2}$. All subjects signed a consent form approved by the Ethics Committee.

\section{Procedures}

The same test developed by Perin et al.(2013) was used. In this test, prominent markers attached in three different vertebrae were used to measure five angles that delimit mobility points of the thoracic spine, lumbar spine and hip joint. This method of quantification of body segments in flexion of the trunk during the execution of SR allowed to establish classification parameters that indicate movement patterns according to the interaction between the involved muscles groups. Before recruitment of subjects, this study met all requirements of Resolution 196/96 of the National Health Council of Brazil and had its protocol approved by the Ethics Committee in Research of the Campos Andrade University Center, document number 422.

Three markers like "elbows" Polystyrene $90^{\circ}$ Fame ${ }^{\circledR}$ brand have been selected in order to delimit points of the spine. These elbows are used in construction to protect electrical wiring. They have considerably little weight, shape similar to the letter "L" with $90^{\circ}$ angle and rods measuring four centimeters long. By presenting such characteristics, they are easily recognized in the digital image and were considered ideal for adhering to the skin surface in the dorsal region using double sided adhesive tape (Figure 1).

A standard box Terrazul® brand seat has been used to measure the amplitude stretching of the posterior trunk and hamstrings. This box is made of wood and is 31 centimeters tall, 64.50 centimeters long and 40 centimeters wide. At its higher base there is a metric scale of 50 centimeters with a sliding mobile device that allows the measuring of subjects range.

Through the technique of palpatory anatomy the fifth lumbar vertebra, twelfth thoracic vertebra and the seventh cervical vertebra were identified all marked with nine millimeters circular markers.

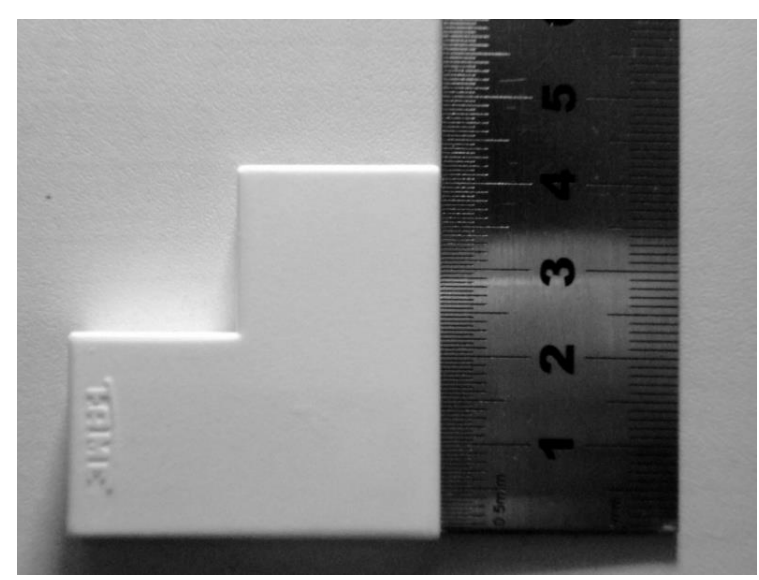

Figure 1. Marker type "elbow"

Thus, it has been requested to the subjects to take a standing position and to perform a trunk flexion for placement of the markers like "elbows". One of the rods of the first marker was affixed with double-sided tape, on the plateau region corresponding to the fifth lumbar vertebra. Similarly, the second marker was placed on the plateau of the twelfth thoracic vertebra and the third marker on the plateau of the seventh cervical vertebra.

After the markings, the volunteer was instructed to execute the SR. The initial and final positions were captured using digital images. The distance between the camera and the subject and the height of the camera from the floor were measured with tape-measure and marked. These measures were standardized and all subjects were photographed with the same camera distance and height, $2.30 \mathrm{~m}$ and $1.10 \mathrm{~m}$, respectively.

The captured images were imported into the software called ImageJ free access 1.4, which allowed the adjustment of the image to the axis $90^{\circ}$ and the measurement of angles through tools called "straight" and "angle tool". Five angles were created to identify the partici- 
pation of different segments of the spine in trunk flexion generated by execution of test SR.

The first created angle was called "Fqlt", which represented the total trunk flexion (hip, lumbar and thoracic). It was necessary to draw a line on top of the marker rod that made the projection of seventh cervical vertebra location and draw another line perpendicular to the vertical plane, starting from the end of the first line in order to measure it.

The second angle was the "Fql" which aimed to identify the angle of hip and lumbar flexion. Like the first angle, one line was traced on top of the marker rod that was on the twelfth thoracic vertebra plateau and another one on the horizontal plane.

The third studied angle, "Fq", identified only hip flexion. The line passing close to the marker with other perpendicular line has been also used to form it.

Based on the three main angles, "Fl" (lumbar flexion angle) was obtained from the subtraction of "Fq" from "Fql", and angle "Ft" (thoracic flexion angle), from the subtraction of "Fql" from "Fqlt" (Figure 2).

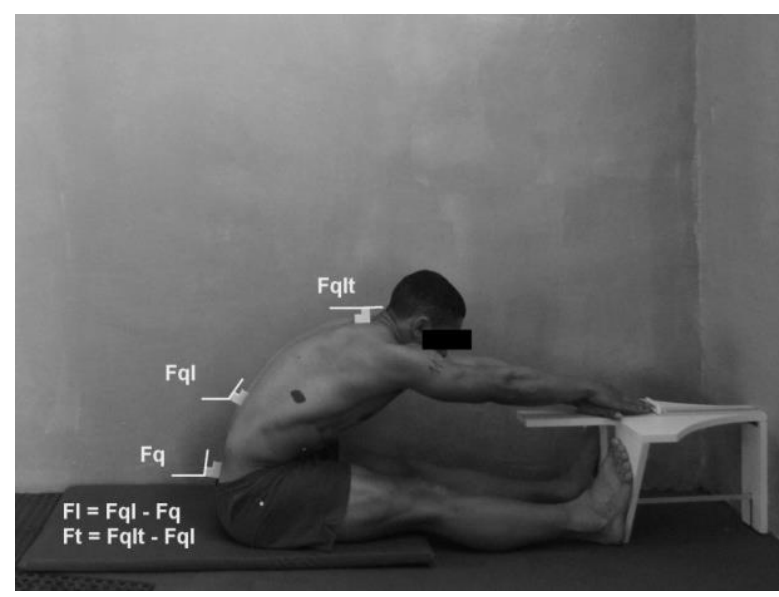

Figure 2. Execution of SR with the angles formed by the markers

To identify the percentage contribution of each segment to the total trunk flexion, the quotient of Fq/Fqlt was multiplied by 100 , resulting in the percentage of the hip. Then, the same procedure was done with the quo- tient of $\mathrm{Fl} / \mathrm{Fqlt}$, finding the percentage of the lumbar region. Finally, the $\mathrm{Ft} / \mathrm{Fqlt}$ quotient was multiplied by 100 , resulting in the percentage of the thoracic region.

\section{Statistical analysis}

The measured angles values of each subject and the relevant results to the assessment were copied to a SPSS version 20 spreadsheet, which generated descriptive statistics, consisting of the presentation of mean, standard deviation, minimum, maximum and variance of collected data. Exploratory statistics was applied to identify if some data presented normal distribution curve.

In addition, the Kolmogorov-Smirnov test has been applied which has verified the normality of the sample and has allowed the application of the Pearson correlation test, with significance level of $\mathrm{p}<0.05$ and $\mathrm{p}<0.01$, which has aimed to infer the correlation level between the variables.

\section{RESULTS}

Regarding variables, the SR presented $20.11 \mathrm{~cm}$ in average. This result fits into the category "Poor" in the reference standard classification of the Canadian Standardized Test of Fitness (1986) and it is classified in the category "good" in the Pollock and Wilmore (1993) protocol. The angles Fq, Fql and Ft have very similar standard deviations with a variation of approximately $13^{\circ}$ in all of them (Table 1 ).

Participation in the hip movement during the SR had the highest percentage, followed by thoracic spine percentage and, finally, the low back. However, the percentage of the trunk, given by the sum of thoracic and lumbar spine percentages $(53.985 \%)$ is higher than the percentage of the hip.

Table 2 refers to the correlation between the angles Fq, Fql, Fqlt, Fl, Ft and the value of $\mathrm{SR}$. Note that there is a moderate positive correlation between Fq, Fql, Fql and SR, more evident among Fql and SR $(r=0.807)$. The angle Fqlt obtained a moderate to low correlation with the other data. 
Table 1

Descriptive statistics of variables

\begin{tabular}{ccccc}
\hline & Mean & Standard Deviation \pm & Variance & $\begin{array}{l}\text { Standard } \\
\text { Error }\end{array}$ \\
\hline SR $(\mathrm{cm})$ & 20.105 & 9.566 & 91.526 & 0.685 \\
$\mathrm{Fq}^{\circ}$ & 76.623 & 13.064 & 170.689 & 0.935 \\
$\mathrm{Fql}^{\circ}$ & 97.717 & 13.570 & 184.162 & 0.971 \\
$\mathrm{Fqlt}^{\circ}$ & 166.722 & 14.955 & 194.743 & 0.999 \\
$\mathrm{Fl}^{\circ}$ & 21.093 & 8.535 & 72.852 & 0.611 \\
$\mathrm{Ft}^{\circ}$ & 69.005 & 13.639 & 186.025 & 0.976 \\
PercentageHips & 46.014 & 7.323 & 53.632 & 0.524 \\
PercentageLumbar & 12.676 & 5.115 & 26.164 & 0.366 \\
PercentageThoracic & 41.309 & 7.189 & 51.684 & 0.514 \\
\hline
\end{tabular}

Table 2

Correlation between the angles and the $S R$

\begin{tabular}{ccccccc}
\hline & SR & Fq & Fql & Fqlt & Fl & Ft \\
\hline SR & - & $0.723^{* *}$ & $0.807^{* *}$ & $0.534^{* *}$ & $0.177^{*}$ & $-0.257^{* *}$ \\
Fq & $0.723^{* *}$ & - & $0.795^{* *}$ & $0.425^{* *}$ & $-0.266^{* *}$ & $-0.357^{* *}$ \\
Fql & $0.807^{* *}$ & $0.795^{* *}$ & - & $0.509^{* *}$ & $0.373^{* *}$ & $-0.474^{* *}$ \\
Fqlt & $0.534^{* *}$ & $0.425^{* *}$ & $0.509^{* *}$ & - & $0.160^{*}$ & $0.516^{* *}$ \\
Fl & $0.177^{*}$ & $-0.266^{* *}$ & $0.373^{* *}$ & $0.160^{*}$ & - & $-0.207^{* *}$ \\
Ft & $-0.257^{* *}$ & $-0.357^{* *}$ & $-0.474^{* *}$ & $0.516^{* *}$ & $-0.207^{* *}$ & - \\
\hline
\end{tabular}

${ }^{*}$ Statistic significance $(p<0.05)$

** Statistic significance $(p<0.01)$

There was a negative correlation between the angles $\mathrm{Ft}$ and $\mathrm{Fq}(\mathrm{r}=-0.357)$, and between $\mathrm{Ft}$ and Fql $(\mathrm{r}=-0.474)$. Suggesting that there is a tendency that the higher the utilization of the hip, the lower the use of thoracic spine in flexion of the trunk.

This fact can also be confirmed by Figure 3, which shows the inverse relationship between the percentage of hip and the percentage of thoracic spine, resulting in the strong and negative correlation between these variables $(\mathrm{r}=$ -0.752).

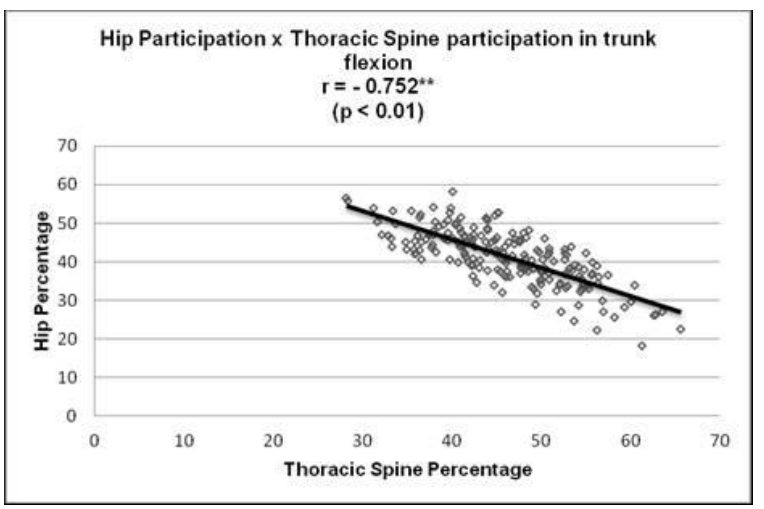

Figure 3. Relationship between hip participation and participation of the thoracic spine in flexion of the trunk

Table 3

New reference standard: classification of angles Fq. Fl and Ft and percentages in five categories.

\begin{tabular}{cccccc}
\hline Angles & Poor & BelowtheAverage & Average & Good & Excellent \\
\hline Fq & $\leq 63.4^{\circ}$ & $63.5^{\circ}-76.6^{\circ}$ & $76.7^{\circ}-89.7^{\circ}$ & $89.8^{\circ}-102.8^{\circ}$ & $\geq 102.9^{\circ}$ \\
Fl & $\leq 12.5^{\circ}$ & $12.6^{\circ}-21.0^{\circ}$ & $21.1^{\circ}-29.6^{\circ}$ & $29.7^{\circ}-38.1^{\circ}$ & $\geq 38.2^{\circ}$ \\
Ft & $\geq 96.3^{\circ}$ & $96.2^{\circ}-82.7^{\circ}$ & $82.6^{\circ}-69.1^{\circ}$ & $69.0^{\circ}-54.4^{\circ}$ & $\leq 54.3^{\circ}$ \\
\hline Percentages & Poor & BelowtheAverage & Average & Good & Excellent \\
\hline Hip & $\leq 38.6 \%$ & $38.7 \%-46.0 \%$ & $46.1 \%-53.3 \%$ & $53.4 \%-60.6 \%$ & $\geq 60.7 \%$ \\
Lumbar & $\leq 7.4 \%$ & $7.5 \%-12.6 \%$ & $12.7 \%-17.7 \%$ & $17.8 \%-22.8 \%$ & $\geq 22.9 \%$ \\
Thoracic & $\geq 55.6 \%$ & $55.5 \%-48.5 \%$ & $48.4 \%-41.4 \%$ & $41.3 \%-34.2 \%$ & $\leq 34.1 \%$ \\
\hline
\end{tabular}


Since the angular data shows a normal curve, from the average value and the standard deviation five categories were created in order to classify angle values Fq, Fl and Ft and percentage values (Table 3 ).

The created categories were: "Poor," "Below Average," "Average", "Good" and "Excellent." The greater the angular value of $\mathrm{Fq}$ and $\mathrm{Fl}$, the better the rating. In contrast, because of the inverse relationship of the hip and the thoracic previously reported, the larger the value of Ft, the worse the rating.

\section{DISCUSSION}

The results showed that the $\mathrm{Fq}$ angle, which is the total hip flexion, was $76.623^{\circ}$ and the angle of trunk flexion, given by the sum of the angles $\mathrm{Fl}$ and $\mathrm{Ft}$, was $90.098^{\circ}$. According to the American Academy of Orthopedics (1965), the angle amplitude of hip flexion starts from $0^{\circ}$ to $120^{\circ}$ and thoracic flexion from $0^{\circ}$ to $80^{\circ}$. Boone and Azen(1979) in their study of 109 men aged 1.5 years to 54 years, found that the average hip flexion to 53 men who were 19 years old or less, was $123.4^{\circ}$.

Kendall et al. (2007), refer the normal hamstring length allows the pelvis to make a flexion in the direction of thighs so that it formed an angle of $80^{\circ}$ of the sacrum with the horizontal axis.

Comparing the data with the classification of angular measurements for men from Leighton (1987), it was observed that the angular value of $\mathrm{Fq}$ falls in the category "average", and the value of trunk flexion ( $\mathrm{Fl}$ added to $\mathrm{Ft}$ ), classified as "moderately high". This classification has five categories: low, moderately low, medium, moderately high and high.

Considering this, it's possible to observe that the amplitude of the hip, on average, was lower than the levels considered normal or high by the literature. This fact reflects the behavior of the trunk during movement because when both body segments are required together one of them tries to compensate for insufficient action on the other.
This synchronization between the movements of the hips and trunk is called lumbopelvic rhythm. In the progression of trunk flexion, lumbar curvature reverses itself, flattens and its curving is moved in the opposite direction. This change goes so far that the lower back takes a rounded shape and total flexion trunk is finished. To follow this new position of the lumbar vertebrae sacrum flexion happens, the pelvis anteversion, and finally a sacral extension (Hamill \& Knutzen, 2008).

This can also be analyzed in relation to the percentage that showed that the participation of the hip in trunk flexion was the highest $(46.014 \%)$. However, the percentage followed very closely the thoracic region $(41.309 \%)$ and, finally, lumbar spine $\left(12.676^{\circ}\right)$, that together (53.985\%) exceeded the percentage participation of the hip.

Chillón et al. (2010) evaluated the contributions of the main joints involved in the movement of trunk flexion with a valuation methodology similar to the present study. The angular kinematic analysis and evaluation of the angles of the hip, lumbar and thoracic. However, the flexibility test used was a modified SR called Back-Saver Sit-and-Reach, where the legs are evaluated separately. The authors reported that the hip angle was responsible for $42 \%$ of the variation in movement in SR modified, the lumbar spine by $30 \%$ and thoracic spine by only $4 \%$, concluding that the flexibility of the hip is the main determinant of trunk flexion.

According to Kapandji (2000), , primarily vertebral muscle contraction occurs during trunk flexion, therefore the gluteus and finally the hamstring. At the end of flexion, there is a stabilization of the spine through the action of passive vertebral ligaments that adopt the pelvis as a fixed point, which anteversion is retained by action of the hamstring muscles.

Thus, if a person's hamstrings are shortened, its tensile strength prevents progress in the pelvis anterior tilting motion, forcing it to resist to the opposing force. Thus, through the cumulative bending of the vertebrae creates a 
false impression that the level of hamstring flexibility is appropriate (Alter, 1991).

The strong correlation found between the SR and Fql angle $(r=0.807)$ and angle $\mathrm{Fq}(\mathrm{r}=$ 0.723 ), suggests that the higher the value obtained in the SR, the greater the value of $\mathrm{Fq}$ and Fql. Some studies also proposed to relate the result obtained by trunk flexion movement through the SR with an angular analysis to obtain a test that had more reliability in the results. One of them was Cornbleet and Woolsey (1996), who evaluated the angle of hip flexion with an inclinometer during movement of the SR in 410 children aged 5 to 12 years and the correlation between them was $r=$ 0.76 .

In a very similar study to the above, the angle of hip flexion was assessed by kinematic analysis and found a correlation with the SR $\mathrm{r}$ $=0.48$ with the ankle in dorsiflexion and $\mathrm{r}=$ 0.44 with ankle flexion planting (Kawano et al., 2010). Perin et al. (2012) also used a kinematic analysis performed using the technique of Biophotogrammetry and found the angle of hip flexion, a moderate correlation with the SR $(\mathrm{r}=0.64)$.

Besides the use of the evaluation angle, other studies have proposed the use of clinical trials to confirm the effectiveness of SR or modifications to the test methodology to obtain more reliable data about the flexion of the trunk and hamstring flexibility. Jackson and Baker (1986), in their research, showed that the SR is a valid measure for the flexibility of the hamstrings as well as highly reproducible, however, it was poorly correlated with a clinical measure of flexibility in the lumbar region, indicating that this test is not valid for that region.

Liemohn et al. (1994) examined the criterion validity of the SR and its modified version Backer-Saver Sit-and-Reach. The subjects were 40 undergraduate students. They used an inclinometer to measure flexibility lumbosacral and flexibility of the hip joint. Although the criterion validity of both tests have been identified as measures of hamstring flexibility $(r=$
$0.70-0.76)$, a consistent criterion validity related to the flexibility of the lumbar spine ( $\mathrm{r}=$ $0.29-0.40$ ) has not been found.

Simoneau (1998) determined in his study which anthropometric components and which body segments flexibility contributed to better performance of the SR. Different tests of flexibility were performed, the first one was the SR itself, followed by Schober-Lumbar flexibility of the lumbar spine, Schober-Lumbar Trunk and flexibility for the thoracic and lumbar spine, the passive straight leg raising test for hamstring and test ankle dorsiflexion flexibility to the ankle plantar flexor. In the Simoneau's results, it was found that the length of the arm and leg were not associated with the performance of SR. Thus, their performance were almost exclusively determined by the flexibility of the hamstrings. In addition, the flexibility of the ankle plantar flexor and lumbar spine was poorly correlated, indicating the need for more specific tests for each muscle group.

Only the study of Chillón et al. (2010), demonstrated the possibility of evaluating the lumbar flexibility along with the flexibility of the hip through the modified SR but it was necessary to use also the angular kinematic analysis to perform it.

The negative correlation between $\mathrm{Ft}$ and $\mathrm{Fq}$ $(\mathrm{r}=-0.357)$ and $\mathrm{Ft}$ and $\mathrm{Fql}(\mathrm{r}=-0.474)$ refers once again to the concept of opposition between the behavior of the hip and the behavior of the thoracic spine. Nevertheless, the correlation between the percentage of thoracic spine and hip $(r=-0.752)$ enhances this point with more emphasis.

López-Miñarro et al. (2009) reported that the posture of the thoracic region can influence the result of the SR and their modified versions. Likewise, Liemohn et al. (1994) also indicated that the test score is influenced by the spine and can alter its validity.

Therefore, it is noted that the flexibility of the trunk flexion and, in particular of hamstring, are extremely difficult to evaluate without the influence of other parts of the body such as the spine. For the interrelationship of 
the muscle, the compensation mechanism generated between them and factors related to muscle imbalance may request different muscle groups to perform the movement (kendall et al., 2007).

So it is important to know the influence or participation of the different body segments in order to identify which muscles are in action. Thus, the reference pattern becomes essential to indicate the presence or absence of normal flexibility of the trunk flexion.

The classification tables for both angles, as to the percentages developed in the present study, the division of the values into five categories, which range from "poor" to "excellent" in order to make the identification of presence of adequate flexibility, presence of compensation and movement pattern.

Since the SR considers only the value obtained on the bench, it ignores the behavior of body segments that influence the movement of trunk flexion. Thus, only this score does not allow the proper prediction of the flexibility level of hamstring muscles.

\section{CONCLUSION}

With this study, it was verified that the development assessment methodology that used resources as surface markers and the use of digital image was effective to monitor the spatial displacement of the segments of the spine and hip during trunk flexion. Moreover, the use of kinematic analysis obtained by photogrammetry allowed quantifying the movement, by determining angular values and percentage contribution of body segments in the execution of SR.

The negative correlation between the behavior of the hip and thoracic spine indicated a relation of opposition between these two regions, which may result in a compensatory mechanism. Thus, it is recommended that evaluation of flexion of the thoracic spine, lumbar spine and hip is performed separately by photogrammetry, based on the average parameters and protocol established in this study, by classifying their values in the pro- posed categories. This way it will be possible to estimate the contribution of movement in joints, favoring the identification of compensatory mechanisms and muscle shortening.

\section{Aknowledgments:}

Nothing to declare

Conflict of Interests:

Nothing to declare

\section{Funding:}

Nothing to declare

\section{REFERENCES}

Alter, M. J. (1991). Ciência Da Flexibilidade (2 Ed.). Porto Alegre: Artes Médicas Sul.

American Academy Of Orthopaedic, S. (1965). Joint Motions, Method of Measuring And Recording. Joint Motion Method Of Measuring And Recording. Chicago.

Ayala, F., \& Sainz, P. B. (2011). Fiabilidad Absoluta De Las Pruebas Sit And Reach Modificado Y Back Saber Sit And Reach Para Estimar La Flexibilidad Isquiosural Em Jugadores De Fútbol Sala. Apunts Medicina De L'Esport, 46, 81-88.

Baltaci, G., Un, N., Tunay, V., Besler, A., \& Gerçeker, S. (2003). Comparison Of Three Different Sit And Reach Tests For Measurement Of Hamstring Flexibility In Female University Students. British Journal of Sports Medicine, 37, 59-61.

Boone, D. C., \& Azen, S. P. (1979). Normal Range Of Motion Of Joints. The Journal Of Bone And Joint Surgery, 61(5), 756-759.

Cailliet, R. (1988). Low Back Pain Syndrome (4 Ed Ed.). Philadelphia.

Cardoso, J. R., Azevedo, N. C. T., Cassano, C. S., Kawano, M. M., \& Âmbar, G. (2007). Confiabilidade Intra $\mathrm{E}$ Interobservador $\mathrm{Da}$ Análise Cinemática Angular Do Quadril Durante O Teste Sentar E Alcançar Para Mensurar O Comprimento Dos Isquiotibiais Em Estudantes Universitários. Revista Brasileira De Fisioterapia, 11, 133-138.

Castro-Piñero, J., Chillón, P., Ortega, F. B., Montesinos, J. L., Sjöström, M., \& Ruiz, J. R. (2009). Criterion-Related Validity Of Sit-AndReach And Modified Sit-And-Reach Test For 
Estimating Hamstring Flexibility In Children And Adolescents Aged $6-17$ Years. International Journal Of Sports Medicine, 30, 658-662.

Chillón, P., Castro-Piñero, J., Ruiz, J. R., Soto, V. M., Carbonell-Baeza, A., Dafos, J., . . Ortega, F. B. (2010). Hip flexibility Is The Main Determinant Of The Back-Saver Sit-And-Reach Test In Adolescents. Journal Of Sports Sciences, 28(6), 641-648.

Chung, P. K., \& Yuen, C. K. (1999). CriterionRelated Validity Of Sit-And-Reach Tests In University Men In Hong Kong. Perceptual And Motor Skills, 88, 304-316

Cornbleet, S. L., \& Woolsey, N. B. (1996). Assessment Of Hamstring Muscle Length In School-Aged Children Using The Sit-AndReach Test And The Inclinometer Measure Of Hip Joint Angle. Physical Therapy In Sport, 76, 850-855.

Danny, P., Chu, K., Luk, T. C., \& Hong, Y. (1998). Emg Activities Between Sit-And-Reach And Stand-And-Reach: A Pilot Study. Paper Presented At The Proceedings of The 20thannual International Conference Of The Ieee Engineering In Medicine And Biology Society.

Davis, D. S., Ashby, P. E., Mccale, K. L., Mcquain, J. A., \& Wine, J. M. (2005). The Effectiveness Of 3 Stretching Techniques On Hamstring Flexibility Using Consistent Stretching Parameters. Journal of Strength And Conditioning Research, 19(1), 27-32.

Hamill, J., \& Knutzen, K. M. (2008). Bases Biomecânicas Do Movimento Humano (2 Ed.). Barueri: Manole.

Hoeger, W. W. K., Hopkins, D. R., Button, S., \& Palmer, T. A. (1990). Comparing The Sit And Reach With The Modified Sit And Reach In Measuring Flexibility In Adolescents. Pediatric Exercise Science, 2, 156-162.

Jackson, A. W., \& Baker, A. A. (1986). The Relationship Of The Sit And Reach Test To Criterion Measures Of Hamstring And Back Flexibility In Young Females. Research Quarterly For Exercise And Sport, 57(183186).

Jones, C. J., Rikli, R. E., Max, J., \& Noffal, G. (1998). The Reliability And Validity Of A Chair Sit-And-Reach Test As A Measure Of Hamstring Flexibility In Older Adults. Research Quarterly For Exercise And Sport, 69, 338-343.

Kapandji, A. I. (2000). Fisiologia Articular: Esquemas Comentados De Mecânica Humana (5 Ed. Vol. 3). Rio De Janeiro: Guanabara Koogan.

Kawano, M. M., Ambar, G., Oliveira, B. I. R., Boer, M. C., Cardoso, A. P. R. G., \& Cardoso, J. R.
(2010). Influence Of The Gastrocnemius Muscle On The Sit-And-Reach Test Assessed By Angular Kinematic Analysis. Revista Brasileira De Fisioterapia, 14, 10-15.

Kendall, F. P. (1965). A Criticism Of Current Tests And Exercises For Physical Fitness. Physical Therapy, 45, 187-197.

Kendall, F. P., Mccreary, E. K., Provance, P. G., Rodgers, M. M., \& Romani, W. A. (2007). Músculos: Provas E Funções Com Postura E Dor (5 Ed.). Barueri: Manole.

Leighton, J. R. (1987). Musculação: Aptidão Física, Sedenvolvimento Corporal E Condicionamento Físico. Rio De Janeiro: Sprint.

Lemmink, K. A. P. M., Kemper, H. G. C., Greef, M. H. G., Rispens, P., \& Stevens, M. T. (2003). The Validity Of The Sit-And-Reach Test And Modified Sit-And-Reach Test In Middle-Aged To Older Man And Women. Research Quarterly For Exercise And Sport, 74, 331-336.

Liemohn, W. P., Sharpe, G. L., \& Wasserman, J. (1994). Criterion-Related Validity Of The SitAnd-Reach Test. Journal of Strength And Conditioning Research, 8, 91-94.

López-Miñarro, P. A., Andújar, P. S. B., García, P. L. R., \& Toro, E. O. (2007). A Comparison Of The Spine Posture Among Several Sit-AndReach Test Protocols. Journal Of Science And Medicine In Sport, 10, 456-462.

López-Miñarro, P. A., Andújar, P. S. B., \& R., G. P. L. (2009). A Comparison Of The Sit-AndReach Test And The Back-Saver Sit-And-Reach Test In University Students. Journal Of Sports Science And Medicine, 8, 116-122.

Miyazaki, J., Murata, S., Horie, J., \& Suzuki, S. (2010). Relationship Between The Sit-AndReach Distance And Spinal Mobility And Straight Leg Raising Range. Rigakuryoho Kagaku, 25, 683-686.

Patterson, P., Wiksten, D. L., Ray, L., Flanders, C., \& Sanphy, D. (1996). The Validity And Reliability Of The Back Saver Sit-And-Reach Test In Middle School Girls And Boys. Research Quarterly For Exercise And Sport, 67, 448-451.

Perin, A., Neves, E. B., \& Ulbricht, L. (2013). Protocolo De Avaliação Do Nível De Flexibilidade Dos Isquiotibiais Por Fotogrametria. Revista Brasileira De Inovação Tecnológica Em Saúde, 3(1), 1-14.

Perin, A., Ulbricht, L., Ricieri, D. V., \& Neves, E. B. (2012). Utilização Da Biofotogrametria Para A Avaliação De Flexibilidade De Tronco. Revista Brasileira De Medicina Do Esporte, 18(3), 176180.

Pollock, M. L., \& Wilmore, J. H. (1993). Exercícios $\mathrm{Na}$ Saúde $E \mathrm{Na}$ Doença: Avaliação $E$ Prescrição Para Prevenção E Reabilitação (2 Ed.). Rio De Janeiro: Medsi. 
162 | A Perin, L Ulbricht, EB Neves

Simoneau, G. G. (1998). The Impact Of Various Anthropometric And Flexibility Measurements On The Sit-And-Reach Test. Journal of Strength And Conditioning Research, 12, 232237.
Sport, F. A. A. (1986). Canadian Standardized Test Of Fitness (Cstf) Operations Manual (3 Ed.). Ottawa: Minister Of State quando especificado em contrário e nos conteúdos retirados de outras fontes bibliográficas. 